\title{
Identifikasi Minat Siswa dalam Belajar Materi Hubungan Antara Bentuk dan Fungsi Bagian Tubuh Hewan dan Tumbuhan
}

\author{
Asro ${ }^{1}$ \\ ${ }^{1}$ SD Negeri 122/IX Petaling
}

\begin{tabular}{l} 
Article Info \\
\hline Article history: \\
Received Dec 29, 2019 \\
Revised Dec 31, 2019 \\
Accepted Jan 01, 2020 \\
\hline
\end{tabular}

Keywords:

Minat

Siswa

Tubuh Hewan dan Tumbuhan

\begin{abstract}
Tujuan Penelitian: Untuk mengetahui minat siswa dalam belajar pada materi hubungan antara bentuk dan fungsi bagian tubuh hewan dan tumbuhan di kelas IV SD Negeri 122/IX Petaling
\end{abstract}

Metodologi: menggunakan korelatif asosiatif desain kuantitatif. Dimana jumlah semua sampel dari penelitian ini adalah 35 siswa. Di mana mereka dipilih menggunakan teknik purposive sampling. Data kemudian dianalisis dengan bantuan aplikasi SPSS 21 untuk menemukan statistik deskriptif dalam bentuk mean, median, min, maks, dan kategori.

Hasil Temuan: Dapat dilihat bahwa hasil minat siswa pada kategori dominan adalah baik

Keterbaruan Penelitian: Siswa perlu diberikan kesempatan untuk mengembangkan pengalaman langsung dalam kegiatan pembelajaran. Para guru harus memanfaatkan strategi pembelajaran agar dapat mengembangkan berbagai kemampuan didalam pembelajaran

This is an open access article under the $\underline{C C B Y-N C}$ license

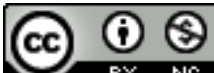

\section{Corresponding Author:}

Asro,

Guru Sekolah Dasar,

SD Negeri 122/IX Petaling,

Jln. Sei Gelam-Petaling Km. 10, Sungai Gelam, Sungai Gelam, Muaro Jambi,

Email: asroasro892@gmail.com

\section{INTRODUCTION}

Pendidikan merupakan salah satu jalan yang harus ditempuh agar tercipta sumber daya manusia yang berkualitas. Especially education for the 21st century in the curriculum of educational institutions is oriented to create productive, creative, innovative, and effective generations through the integration of attitudes, abilities and knowledge with life skills [1-4]. Maka dari itu lembaga pendidikan di negara menetapkan kompetensi sebagai tujuan dari kurikulum [5-6]. Selain itu, praktisi pendidikan dosen menyetujui bahwa pendidikan guru bertujuan dalam mendidik guru berkualitas tinggi yang akan berhasil diintegrasikan kedalam sistem pendidikan [7-8]. Kompetensi global guru sekolah di masa mendatang diharapkan mencakup basis pengetahuan, keterampilan, dan sikap yang mereka perlukan untuk secara efektif melaksanakan tugas profesional mereka di sekolah dan berfungsi secara menguntungkan dalam masyarakat yang berubah dan saling bergantung [9-10].

In learning, attitude is also an aspect that deserves to be taken into account. In the learning process, especially in chemistry lessons, participants' attitudes are important to be rejected [11]. The attitudes of the process are very important [12-13]. Because, students who have this view will have different attitudes, with students who have a positive outlook during the learning process [14-17]. Didalam pembelajaran aspek kognitif dan afektif sangat dibutuhkan, karena siswa yang memiliki afektif yang tinggi akan membuat siswa tersebut menemukan konsep diri, kritis dan kreatif dari seorang siswa. Sikap dapat didefinisikan sebagai 
kecenderungan untuk memberikan reaksi yang dipelajari, konsisten, positif atau negatif terhadap suatu objek [18-21]. [22] mendefinisikan sikap sebagai bagian dari kepribadian individu dipengaruhi oleh perilaku hubungan dengannya. Sikap dapat juga didefinisikan sebagai kecenderungan untuk bertindak terhadap orang, hal, peristiwa, atau ide. Sikap tampak tanpa disadari, berkelanjutan dan terkait erat dengan pendapat. Sikap terbentuk sebagai hasil dari pengalaman belajar yang akan menumbuhkan minat seorang siswa. Telah diamati bahwa banyak siswa saat ini kehilangan minat pada mata pelajaran sains. Ini mengkhawatirkan karena generasi masa depan membutuhkan komunitas masa depan yang baik dalam sains [23-24].

Minat seseorang terkait erat dengan perasaan bahagia. Orang yang tertarik pada sesuatu akan senang dan tanpa sadar akan memperhatikan sesuatu. Diidentifikasi sebagai struktur multidimensi yang mencakup makna kehidupan, hubungan positif, tanggung jawab, perasaan positif, dan kesuksesan. Siswa yang menikmati belajar akan tertarik untuk belajar dan memperhatikan sebagai bentuk menafsirkan kehidupan ketika proses pembelajaran berlangsung. Ketertarikan untuk belajar diartikan apabila seseorang yang berminat terhadap suatu pelajaran maka ia akan memiliki perasaan ketertarikan terhadap pelajaran tersebut [25]. Siswa yang senang dengan pelajaran memiliki perasaan positif dalam proses belajar mereka dan percaya pada keberhasilan mereka, dengan kata lain, siswa yakin untuk mencapai tujuan dan manfaat saat belajar. Pelajaran ini akan selalu ditunggu-tunggu, tugas akan dilakukan dengan baik, dan siswa tidak akan merasa bosan untuk belajar. Suasana belajar yang menyenangkan siswa diciptakan oleh lingkungan sekitar seperti ruang kelas yang rapi, bersih, indah, guru yang baik, perawatan dan pasien, dan metode dan media pengajaran yang tepat sehingga siswa dapat menikmati pelajaran sains. Untuk itu dengan sendirinya, prestasi siswa dalam pelajaran sains akan meningkat tanpa merasakan beban pada siswa. Maka dari itu minat dapat dilihat dari apakah siswa senang atau tidak ketika belajar sains.

Siswa yang senang dan peduli dengan belajar akan berkonsentrasi ketika guru menjelaskan pelajaran. Fokus siswa pada pelajaran akan membuatnya lebih mudah bagi siswa untuk memahami pelajaran dengan cepat sehingga akan ada lebih sedikit hambatan bagi siswa untuk menyelesaikan masalah, terutama dalam sains. Jika minat siswa dalam belajar tinggi, maka perhatian mereka akan dikhususkan untuk pembelajaran penuh. Jika ada kelainan, ia tidak akan mengabaikan kelainan itu dan tetap fokus mendengarkan penjelasan guru. Untuk alasan ini, konsentrasi perhatian penting diterapkan secara maksimal oleh semua siswa sehingga penyampaian materi dapat disampaikan secara optimal dan produktif. Siswa akan menyesal kehilangan pengetahuan yang mereka ajarkan jika mereka tidak menaruh perhatian penuh pada pembelajaran. Tujuannya agar siswa memiliki hasrat yang lebih tinggi untuk belajar sehingga perhatian dalam belajarnya akan semakin lebih baik[25]. Maka dari itu perhatian dalam belajar akan meningkatkan minat siswa pada pelajaran, terutama dalam pelajaran sains.

Jika siswa memiliki kesenangan dan perhatian khusus dalam pelajaran. Sehingga siswa akan mengetahui manfaat dan tujuan dalam belajar dan akan mudah diterima oleh siapa saja. Demikian juga dengan pelajaran sains, jika siswa memahami konsep itu kemudian menerapkannya dalam kehidupan, sehingga siswa akan merasa beruntung untuk mempelajarinya. Melalui pelajaran sains, siswa belajar banyak secara ilmiah untuk memecahkan masalah dalam kehidupan sehari-hari. Salah satu tujuan pembelajaran sains adalah mengembangkan pengalaman untuk dapat merumuskan masalah, menyerahkan dan menguji hipotesis melalui eksperimen, merancang dan merakit instrumen eksperimental, mengumpulkan, memproses, dan menafsirkan data, dan mengkomunikasikan hasil eksperimen secara verbal dan tertulis [26]. Dukungan orang tua di bidang akademik memiliki kemampuan untuk meningkatkan self-efficacy, sikap, dan hasil yang diharapkan di bidang sains dan perawatan di masa depan. minat dan perhatian orangtua terhadap kinerja anak di sekolah merupakan indikator penting dalam sukses anak di sekolah [25]. Besarnya manfaat pelajaran sains terutama pada tingkat pendidikan sekolah dasar adalah untuk mengembangkan pengetahuan dan membuatnya lebih mudah untuk menciptakan sesuatu di masa sekarang. Hal ini tentunya dipandu oleh mereka yang memberikan instruksi agar siswa dapat terus belajar dalam ranah kognitif. Instruksi merangsang kognitif harus membangkitkan dan mempertahankan minat siswa dalam alasan teoritis. Dengan instruksi dari guru, siswa akan bereksperimen dan belajar lebih teratur. Melalui pengalaman dan pengetahuan tentang manfaat belajar sains, siswa akan tertarik mempelajari sains karena dianggap penting untuk menghasilkan kreativitas ilmiah.

Selain aspek afektif, kurikulum saat ini juga menekankan aspek kognitif, terutama dalam keterampilan berpikir kreatif. Meskipun berpikir kreatif termasuk elemen kognitif dan afektif seperti cara berpikir lain, itu terutama melibatkan penggunaan proses kognitif [25]. Karena pelajaran sains fokus pada pelatihan berpikir dan bernalar, mengembangkan kegiatan kreatif, mengembangkan keterampilan pemecahan masalah dan mengkomunikasikan gagasan. Keterampilan berpikir kreatif secara inheren berfungsi kognitif normatif daripada bawaan tersedia hanya beberapa talenta [27-30].

Kurangnya minat untuk belajar siswa, terutama dalam mata pelajaran sains, menjadi kenyataan yang lebih umum saat ini [31]. Dalam konteks pembelajaran keterampilan berpikir kreatif terkait erat dengan cara mengajar guru di sekolah. Guru menjadi faktor utama di sekolah dan orang tua menjadi penentu di rumah dan 
lingkungan dalam menumbuhkan kreativitas anak-anak. Namun kenyataan di lapangan menunjukkan bahwa pembelajaran yang dilakukan oleh guru, masih menerapkan paradigma lama tentang dimensi proses kognitif. Dalam hal ini, dalam pembelajaran guru masih mengandalkan enam proses, yaitu: memori, pemahaman, aplikasi, analisis, sintesis, dan evaluasi. Definisi kreativitas matematika yang dibangun di dunia barat adalah proses yang membuka pintu baru, pengetahuan / pemahaman yang tidak biasa dan mendalam yang dibangun melalui pemecahan masalah, sedangkan dalam pandangan dunia timur kreativitas berfokus pada penafsiran ulang. masalah yang dilihat dari sudut yang berbeda. Definisi kreativitas adalah proses pemikiran domain tertentu yang digunakan oleh ahli sains ketika mereka memecahkan masalah sains yang tidak teratur.

Tujuan dari penelitian ini adalah untuk melihat Minat Siswa Dalam Belajar Materi Hubungan Antara Bentuk Dan Fungsi Bagian Tubuh Hewan Dan Tumbuhan.

\section{RESEARCH METHOD}

Desain penelitian yang digunakan dalam penelitian ini adalah metode penelitian Asosiatif Kuantitatif dengan desain penelitian korelasional. Penelitian kuantitatif asosiatif adalah penelitian yang bertujuan untuk mengetahui hubungan antara dua variabel atau lebih [32]. Karena penelitian ini adalah penelitian asosiatif, maka peneliti mengambil desain penelitian korelasional. Menurut ref [33] "Desain Korelasi adalah prosedur dalam penelitian kuantitatif yang digunakan oleh peneliti untuk mengukur tingkat asosiasi (hubungan) antara dua variabel atau lebih menggunakan prosedur analisis korelasi statistik".

Sampel penelitian ini diperoleh dari 35 siswa sekolah dasar diambil dengan teknik purposive sampling dengan rincian 20 siswa perempuan dan 15 siswa laki-laki. Pengambilan sampel Purposive adalah teknik pengambilan sampel berdasarkan kriteria peneliti [34].

Dalam penelitian ini, penelitian ini menggunakan instrumen kuesioner dan pilihan ganda. Kuisioner minat yang diadopsi dari Christidou (2011) memiliki pernyataan yang valid dengan menggunakan skala Likert 4 (lima) untuk pernyataan positif Sangat Tidak Setuju memiliki skor 1, Tidak setuju memiliki skor 2, Setuju memiliki skor 3 dan Sangat Setuju 4 Untuk pernyataan negatif Sangat Tidak Setuju memiliki skor 4, Tidak setuju memiliki skor 3, skor 2 dan Sangat Setuju memiliki skor 1.

Data yang digunakan oleh program SPSS untuk mencari statistik deskriptif dan inferensial. Statistik deskriptif disajikan dalam frekuensi ringkasan, misalnya mode, mean, median, minimum, maksimum dan standar deviasi [35]. Kesimpulan statistik dari prosedur matematika untuk menggunakan probabilitas dan informasi tentang sampel untuk menarik kesimpulan tentang populasi dari mana sampel mungkin diambil [36]. Dalam penelitian ini terdapat uji hipotesis, yaitu hipotesis menggunakan korelasi product moment. seperti tabel 1

Kategori-kategori kuesioner minat meliputi, sangat baik, baik, tidak baik, dan sangat tidak baik,

Tabel 1. Kategori minat siswa

\begin{tabular}{cccc}
\hline \multirow{2}{*}{ Kategori } & \multicolumn{3}{c}{ Selang } \\
\cline { 2 - 4 } & Merasa bahagia & Perhatian dalam Belajar & Manfaat Subjek \\
\hline Sangat Tidak Baik & $4,0-6,0$ & $5.0-6.7$ & $5,0-6.7$ \\
Tidak baik & $6.1-8.0$ & $6.8-8.5$ & $6.8-8.5$ \\
Baik & $8.1-10.0$ & $8.6-10.2$ & $8.6-10.2$ \\
Baik sekali & $10.1-12.0$ & $10.3-12.0$ & $10.3-12.0$ \\
\hline
\end{tabular}

Semua data diperoleh dari angket sikap tentang nilai-nilai siswa dan dikumpulkan serta dihitung dan dibantu dengan aplikasi SPSS 21. Statistik deskriptif diberikan untuk menghitung frekuensi, persentase, ratarata, median, min, dan maks sampel [38]. Dalam penelitian ini, data kuantitatif dianalisis menggunakan statistik parametrik momen orang produk. Korelasi momen orang produk untuk menentukan apakah ada minat siswa dalam belajar materi hubungan antara bentuk dan fungsi bagian tubuh hewan dan tumbuhan. Penelitian ini menggunakan SPSS 21 pada tingkat signifikansi 0,05. Dan dilanjutkan dengan wawancara yang digunakan untuk memperkuat hasil data kuantitatif. Dilanjutkan dengan wawancara dimaksudkan untuk memperkuat hasil data kuantitatif. Langkah-langkah dalam wawancara dapat dilihat sebagai berikut: (1) ide, tema, potongan data dan kata-kata. (2) memperhatikan pola dan tema. (3) mencoba membuat data yang baik, menggunakan intuisi untuk mencapai kesimpulan. (4) Apakah kelompok mengatur item ke dalam kategori, tipe, perilaku, dan klasifikasi? (5) membuat metafora yang menggunakan bahasa kiasan dan konotatif daripada bahasa literal dan denotatif, menjiwai data, mengurangi data, membuat pola, menyelaraskan data, menghubungkan data dengan teori. (6) pisyakan variabel untuk menguraikan, membedakan, dan 'membongkar' ide, yaitu berpindah dari drive ke integrasi dan mengaburkan data. (7) menyerah secara khusus ke dalam sejumlah besar variabel di bawah sejumlah kecil (sering) variabel hipotesis yang tidak teramati. (8) mengidentifikasi dan mencatat hubungan antar variabel. (9) menemukan variabel 
intervening: mencari variabel lain yang tampaknya menjadi perhitungan 'blok' untuk apa yang diharapkan menjadi hubungan yang kuat antara variabel. (10) rantai logis pembangunan bukti: mencatat kausalitas dan membuat kesimpulan. (11) Menciptakan koherensi konseptual/teoritis: bergerak dari metode untuk membangun cerita untuk menjelaskan fenomena [38].

\section{HASIL DAN PEMBAHASAN}

Siswa dapat dilihat dari karakteristik siswa itu sendiri, yaitu dari perasaan senang, atau hanya biasa dari siswa dalam menyelesaikan masalah ketika ia belajar. Selain itu, bisa juga dilihat dari perasaan senang, tidak bahagia, suka atau tidak, termotivasi atau tidak termotivasi, tertarik atau tidak. Sikap adalah istilah yang mencerminkan kesenangan, ketidaksenangan, atau perasaan biasa seseorang terhadap sesuatu [49]. Dan sikap minat yang dimiliki siswa mampu menumbuhkan keterampilan berpikir kreatif siswa. Karena keterampilan berpikir kreatif siswa sangat penting untuk dimiliki dalam semua aspek studi pendidikan [40]. Dimana, dalam penelitian ini, yang akan diteliti adalah minat siswa, yaitu perasaan senang dalam belajar, perhatian dalam belajar, dan manfaat jika belajar mata pelajaran.

\subsection{Merasa Bahagia}

Kuesioner minat tentang indikator perasaan bahagia dianalisis menggunakan aplikasi SPSS 21 yang dapat dilihat pada tabel hasil indikator merasa bahagia belajar dalam sains di bawah ini:

Tabel 2 . Hasil Indikator Merasa Bahagia Belajar dalam sains

\begin{tabular}{|c|c|c|c|c|c|c|c|c|c|}
\hline \multicolumn{5}{|c|}{ Klasifikasi } & \multirow{2}{*}{ Berarti } & \multirow{2}{*}{ Median } & \multirow{2}{*}{ Min } & \multirow{2}{*}{ Maks } & \multirow{2}{*}{$\%$} \\
\hline Interval & M. & $\mathrm{F}$ & Bunga & Total & & & & & \\
\hline $4,0-6,0$ & 3 & 2 & Tidak terlalu bagus & 5 & \multirow{4}{*}{8.7} & \multirow{4}{*}{9.00} & \multirow{4}{*}{5.00} & \multirow{4}{*}{11.00} & 9.4 \\
\hline $6.1-8.0$ & 2 & 3 & Tidak baik & 5 & & & & & 21.1 \\
\hline $8.1-10.0$ & 7 & 8 & Baik & 15 & & & & & 42.2 \\
\hline $10.1-12.0$ & 3 & 7 & Baik sekali & 10 & & & & & 27.3 \\
\hline TOTAL & 15 & 20 & & 35 & & & & & 100 \\
\hline
\end{tabular}

Dari tabel 3, yang berasal dari 35 responden dari siswa sekolah dasar negeri 122/IX Petaling dikategorikan baik untuk pria sebanyak 8 siswa dan untuk wanita sebanyak 7 siswa dengan kategori baik, dan setelah diolah dan diperoleh hasil menggunakan aplikasi program SPSS , kemudian, diperoleh perasaan senang belajar memiliki kategori baik 42,1\% untuk 15 siswa dari 35 total siswa, sangat baik 27,3\% untuk total 10 siswa dari 35 total siswa. Tidak Baik pada 11,8\% untuk 5 siswa dari 35 total siswa, dan sangat buruk pada 9,4\% untuk 5 siswa dari 35 total siswa. Dari 35 siswa nilai rata-rata adalah 8,7, rata-rata 9, nilai maksimum adalah 11, dan nilai minimum adalah 5.

Hasil analisis kuesioner pada tabel 3, indikator perasaan senang di sekolah dasar negeri 122/IX Petaling memiliki minat yang baik pada mata pelajaran sains. Perasaan senang diungkapkan oleh siswa dengan rajin mengerjakan tugas sains, siap untuk mengambil pelajaran sains dengan menyelesaikan kebutuhan sebelum belajar, memperhatikan guru mengajar dengan hati-hati dan mengajukan pertanyaan jika mereka mengalami kesulitan belajar karena mereka memiliki rasa ingin tahu yang tinggi.

\footnotetext{
"Apakah kamu menyukai pelajaran sains?”

"Ya, saya suka belajar sains".

"Apa yang membuatmu bahagia ketika pelajaran sains berlangsung?”

"Studi sains sering melakukan eksperimen. Saya suka belajar sains ketika melakukan eksperimen yang menantang dan tidak membosankan seperti pembelajaran di kelas biasa. Saya mendapat ide baru dan sangat puas jika saya bisa mendapatkan jawaban yang saya cari sendiri melalui eksperimen."
}

Berdasarkan hasil wawancara, siswa senang ketika belajar sains karena eksperimen dan tidak sering hanya belajar di kelas. Eksperimen adalah bagian dari pelajaran fisiologi yang disukai oleh siswa. Unsur barang dari segi minat mencakup tiga hal luas yang menarik, perhatian, dan daya dorong. Kesenangan belajar pada siswa adalah salah satu hal utama yang dapat meningkatkan minat siswa . Kesenangan ini berasal dari banyak faktor seperti ruang kelas yang bersih, nyaman dan indah sehingga siswa memiliki pandangan bebas terhadap ruang kelas dengan tidak diganggu oleh kelas kotor. Salah satu kesenangan belajar siswa yaitu siswa tertarik untuk memperbanyak ilmu pengetahuan [41]. Hal lain adalah keterampilan guru dalam mengajar menggunakan metode dan media yang tepat saat menyampaikan pelajaran sehingga siswa cepat memahami materi dan merasa senang mempelajarinya. Dengan itu, ada interaksi antara siswa dan guru seperti 
mengajukan pertanyaan dan siswa dengan teman-teman dalam diskusi. Ini akan membuat siswa tidak bosan ketika belajar di kelas [42]. Terutama ketika melakukan eksperimen, siswa lebih banyak berinteraksi dengan alam dan orang-orang di sekitarnya. Semakin banyak interaksi, semakin banyak hal yang diketahui siswa. maka para siswa akan merasa lebih senang dalam belajar sains dan meningkatkan minat dalam mempelajari sains lebih dalam.

\subsection{Perhatian dalam Belajar}

Kuesioner minat tentang perhatian indikator dalam pembelajaran dianalisis menggunakan aplikasi SPSS 21 yang dapat dilihat pada tabel hasil indikator perhatian belajar sains di bawah ini:

Tabel 3 . Hasil Indikator Perhatian Belajar sains

\begin{tabular}{|c|c|c|c|c|c|c|c|c|c|}
\hline \multicolumn{5}{|c|}{ Klasifikasi } & \multirow[b]{2}{*}{ Berarti } & \multirow[b]{2}{*}{ Median } & \multirow[b]{2}{*}{ Min } & \multirow[b]{2}{*}{ Maks } & \multirow{2}{*}{$\%$} \\
\hline Interval & M. & $\mathrm{F}$ & Bunga & Total & & & & & \\
\hline $4,0-6,0$ & 3 & 2 & Tidak terlalu bagus & 5 & & & & & 9.4 \\
\hline $6.1-8.0$ & 2 & 3 & Tidak baik & 5 & & & & & 21.1 \\
\hline $8.1-10.0$ & 7 & 8 & Baik & 15 & 8.7 & 9.00 & 5.00 & 11.00 & 42.2 \\
\hline $\begin{array}{r}10.1- \\
12.0\end{array}$ & 3 & 7 & Baik sekali & 10 & & & & & 27.3 \\
\hline TOTAL & 15 & 20 & & 35 & & & & & 100 \\
\hline
\end{tabular}

Dari tabel 3, yang berasal dari 35 responden dari siswa sekolah dasar negeri 122/IX Petaling dikategorikan baik untuk pria sebanyak 8 siswa dan untuk wanita sebanyak 7 siswa dengan kategori baik, dan setelah diolah dan diperoleh hasil menggunakan aplikasi program SPSS, kemudian, diperoleh perasaan senang belajar memiliki kategori baik 42,1\% untuk 15 siswa dari 35 total siswa, sangat baik 27,3\% untuk total 10 siswa dari 35 total siswa. Tidak Baik pada 11,8\% untuk 5 siswa dari 35 total siswa, dan sangat buruk pada 9,4\% untuk 5 siswa dari 35 total siswa. Dari 35 siswa nilai rata-rata adalah 8,7, rata-rata 9, nilai maksimum adalah 11, dan nilai minimum adalah 5.

Hasil analisis pada Tabel 3, indikator perhatian sekolah menengah atas dominan menunjukkan minat yang baik. Lebih banyak siswa memberikan perhatian dengan memberikan pembelajaran terbaik, dalam hal ini, pelajaran sains. Siswa ingin memenuhi kebutuhan akan proses pembelajaran sains yang lancar. Dan siswa selalu memperhatikan ketika guru menjelaskan pelajaran.
“Apakah kamu selalu pergi ke kelas ketika pelajaran sains berlangsung?”
"Ya. Setiap kali ada pelajaran sains aku selalu masuk kelas"
"Apa yang kamu lakukan sebagai bentuk perhatian ketika proses pembelajaran berlangsung?"
"Saya selalu mengambil pelajaran sains dan memperhatikan ketika guru menjelaskan. Hal itu karena guru saya ketat dan disiplin ketika mengajar, jadi kita semua memperhatikan pelajaran sampai jam sains selesai meskipun masih ada beberapa yang tidak fokus pada pembelajaran, saya juga selalu bersiap untuk belajar dan alat tulis sebelum belajar sains dimulai."

Berdasarkan hasil wawancara, perhatian siswa dalam belajar sains menunjukkan minat yang baik di mata sains. Siswa yang belajar dengan minat ketika belajar akan memperhatikan antusiasme karena mereka memotivasi diri mereka untuk tertarik pada materi yang dipelajari sehingga kinerja mereka meningkat. Karena posisi mata adalah ukuran yang dapat diandalkan dari alokasi atensi, efek ini memberikan demonstrasi penting dari saling mempengaruhi antara pilihan dan perhatian. Dengan perhatian yang berkelanjutan, itu akan meningkatkan minat siswa dalam belajar yang juga akan meningkatkan prestasi belajar mereka. Menurut asumsi umum bahwa waktu yang baik secara positif terkait dengan perhatian, atau setidaknya, untuk perhatian terbuka. Hasil ini menunjukkan bahwa kemampuan untuk membedakan rangsangan mungkin mengandalkan perhatian yang lebih besar untuk memperhatikan. elemen khas dari rangsangan, yang lebih besar setelah dicampur sebelum diblokir sebelum paparan. Ketika instruksi mendorong peserta untuk mencari perbedaan dalam stimulus, mereka mungkin menampilkan strategi pencarian yang terdiri dari berturut-turut membandingkan daerah stimulasi tertentu[43-45]. Strategi pembelajaran yang diawasi seperti itu dapat memfasilitasi penemuan elemen stimulasi tertentu, sehingga meningkatkan perhatian pada pembelajaran. Jadi siswa akan mempunyai perhatian dalam belajar, jika jiwa dan pikirannya terfokus dengan apa yang ia pelajari [46]. Oleh karena itu, siswa perlu memiliki perhatian khusus untuk dapat mengambil manfaat dari pelajaran. 


\subsection{Manfaat Subjek}

Kuesioner minat tentang indikator dianalisis menggunakan aplikasi SPSS 21 yang dapat dilihat pada tabel hasil indikator manfaat mata pelajaran dalam sains di bawah ini:

Tabel 4. Hasil Indikator Manfaat Mata Pelajaran dalam sains

\begin{tabular}{|c|c|c|c|c|c|c|c|c|c|}
\hline \multicolumn{5}{|c|}{ Klasifikasi } & \multirow[t]{2}{*}{ Berarti } & \multirow[t]{2}{*}{ Median } & \multirow[t]{2}{*}{ Min } & \multirow[t]{2}{*}{ Maks } & \multirow[t]{2}{*}{$\%$} \\
\hline Interval & M. & $\mathrm{F}$ & Bunga & Total & & & & & \\
\hline $4,0-6,0$ & 3 & 2 & Tidak terlalu bagus & 5 & \multirow{4}{*}{8.7} & \multirow{4}{*}{9.00} & \multirow{4}{*}{5.00} & \multirow{4}{*}{11.00} & 9.4 \\
\hline $6.1-8.0$ & 2 & 3 & Tidak baik & 5 & & & & & 21.1 \\
\hline $8.1-10.0$ & 7 & 8 & Baik & 15 & & & & & 42.2 \\
\hline $10.1-12.0$ & 3 & 7 & Baik sekali & 10 & & & & & 27.3 \\
\hline TOTAL & 15 & 20 & & 35 & & & & & 100 \\
\hline
\end{tabular}

Dari tabel 4, yang berasal dari 35 responden dari siswa sekolah dasar negeri 122/IX Petaling dikategorikan baik untuk pria sebanyak 8 siswa dan untuk wanita sebanyak 7 siswa dengan kategori baik, dan setelah diolah dan diperoleh hasil menggunakan aplikasi program SPSS , kemudian, diperoleh perasaan senang belajar memiliki kategori baik 42,1\% untuk 15 siswa dari 35 total siswa, sangat baik 27,3\% untuk total 10 siswa dari 35 total siswa. Tidak Baik pada 11,8\% untuk 5 siswa dari 35 total siswa, dan sangat buruk pada 9,4\% untuk 5 siswa dari 35 total siswa. Dari 35 siswa nilai rata-rata adalah 8,7, rata-rata 9, nilai maksimum adalah 11, dan nilai minimum adalah 5.

Indikator manfaat mata pelajaran di Sekolah dasar negeri 122/IX Petaling memiliki minat yang baik pada mata pelajaran sains. Beberapa siswa sudah tahu manfaat sains. Ini membuat siswa semakin tertarik pada sains.

“Apakah menurut Anda sains tidak perlu diajarkan?”

"tidak. Karena sains memiliki manfaat besar dalam kehidupan ini. Melalui sains, kita bisa tahu lebih banyak tentang teori kehidupan"

"Apa saja contoh sains yang dapat diterapkan dalam kehidupan?”

"Banyak contoh. Salah satu dari mereka tahu bagaimana proses yang terjadi dari es batu, yang awalnya berupa air biasa hingga menjadi beku, yang dapat membantu kita menjadi segar dengan mencampurkan minuman kita”

Berdasarkan wawancara di atas, siswa mendapat manfaat dari belajar sains. Itu bisa dilihat dari cara guru mengajarkan hal yang benar yaitu konsep alam dengan rumus sains yang ada [47-49]. Mengajar siswa untuk menganalisis latar belakang abstrak dengan kondisi konkret untuk memberikan siswa informasi tentang pentingnya ilmu alam dengan konsep-konsep yang diajarkan. Menentukan manfaat dan kegunaan ilmu sains, siswa akan perlu menerapkan sains untuk kehidupan di alam. Dengan itu, sains akan lebih bermanfaat dan tidak hanya terbatas pada mengetahui formula. Siswa akan mencoba mempelajari pengetahuan yang baik. Oleh karena itu, ini adalah antusiasme dan minat siswa untuk belajar sains. Ketika siswa termotivasi dan tertarik untuk belajar sains sejak muda, mereka dapat terus mempelajarinya nanti di universitas yang akan bermanfaat bagi masyarakat masa depan dan dunia pada umumnya [50].

\section{KESIMPULAN}

Dapat dilihat bahwa hasil minat siswa serta indikator perasaan bahagia dan perhatian dalam belajar memiliki kategori baik karena, jika siswa merasa bahagia, atau bahagia di kelas selama proses pembelajaran, siswa akan memiliki lebih banyak perhatian dalam pembelajaran yang akan berdampak salah satunya akan diterima oleh siswa, salah satunya memiliki keterampilan berpikir kreatif. Guru harus memanfaatkan strategi pembelajaran sehingga mereka dapat mengembangkan berbagai keterampilan dan sikap belajar dari siswa seumur hidup.

\section{UCAPAN TERIMA KASIH}

Terima kasih kepada kepala sekolah, staf pengajar serta responden di SD Negeri 122/IX Petaling yang telah berpartisipasi untuk kelancaran penelitian dan terima kasih kepada pihak-pihak yang telah memberi dukungan pada penelitian ini. 


\section{REFERENSI}

[1] V. S. Andrini, "The effectiveness of inquiry learning method to enhance students' learning outcome: A theoritical and empirical review," Journal of Education and Practice, Vol. 7, No. 3, pp. 38-42, 2016 https://eric.ed.gov/?id=EJ1089825

[2] A. R. Kabeel and S. A.-M. Eisa, "The correlation of critical thinking disposition and approaches to learning among baccalaureate nursing student," Journal of Education and Practice, Vol. 7, No. 32, pp. 91-103, 2016 https://eric.ed.gov/?id=EJ1122541

[3] F. Taghva, N. Rezael, J. Ghaderi, and R. Taghva, "Studying the relationship between critical thinking skills and students' educational achievement (Eghlid Universities as case study)". International Letters of Social and Humanistic Sciences, Vol. 25, pp. 18-25, 2014 https://doi.org/10.18052/www.scipress.com/ILSHS.25.18

[4] J. Siburian, A. D. Corebima, Ibrohim, and M. Saptasari, "The Correlation Between Critical and Creative Thinking Skill on Cognitive Learning Results," Eurasian Journal of Educational Researc, Vol. 81, pp. 99-114, 2019 https://doi.org/10.14689/ejer.2019.81.6

[5] N Pantic and T. Wubbels, "Competence-based teacher eduation: A change from Didaktik to Curriculum culture," Journal of Curriculum Studies, Vol. 44, no. 1. Pp. 61-87, 2012 https://doi.org/10.1080/00220272.2011.620633

[6] S. Unlu, "Curriculum Development Study for Teacher Education Supporting Critical Thinking." Eurasia Journal Educational Research, vol. 76, pp. 165-186, 2018 https://doi.org/10.14689/ejer.2018.76.9

[7] H. Ezer, I. Gilat and R. Sagee, "Perception of teacher education and professional identity among novice teachers," European Journal of Teacher Education, Vol. 33, no. 4, pp. 391-404, 2010 https://doi.org/10.1080/02619768.2010.504949

[8] W. Boonjeam, K. Tesaputa, and A. Sri-ampai, "Program development for primary school teachers' critical thinking," International Education Studies, vol. 10, no. 2, pp. 131-138, 2017 http://dx.doi.org/10.5539/ies.v10n2p131

[9] I. M. Signagatullin, "Developing Preservice Elementary Teachers' Global Competence" International Journal of Educational. Vol. 28, no. 1, pp. 48-62, 2019 https://doi.org/10.1177/1056787918824193

[10] Darmaji, D. A.Kurniawan, Astalini, A. Lumbantoruan, and S. C. Samosir, "Mobile Learning In Higher Education For The Industrial Evolutioin 4.0: Perception and Response of Physics Practicum" International Journal of Interactive Mobile (IJIM), Vol. 13, No. 9, pp. 4-20, 2019

[11] Astalini, D. A. Kurniawan, Darmaji, L. R. Sitorus, R. Perdana, "Characteristic Of Students Attitude To Physics In Muaro Jambi High School," Humanities \& Social Science Reviews, Vol. 7, no. 2, pp. 91-99, 2019 https://doi.org/1018510/hssr.2019.7210

[12] D, A. Kurniawan, Astalini., and L. Anggraini, "Evaluasi Sikap SMP Terhadap IPA di Kabupaten Muaro Jambi," Jurnal Ilmiah Didaktika: Media Ilmiah Pendidikan dan Pengajaran, Vol. 19, no. 1, pp. 123-139, 2018 http://dx.doi.org/10.22373/jid.v19i1.4198

[13] Astalini, D. A. Kurniawan, R. Perdana, and D. Kurniasari, "Identification of Student Attitudes toward Physics Learning at Batanghari District High School," The Educational Review, USA, vol. 2, no. 9, pp. 475-484, 2018 http://dx.doi.org/10.26855/er.2018.09.003

[14] Astalini, D. A. Kurniawan, R. Perdana, and Kurniawan, W, "Identification Attitudes of Learners on Physics Subject” EST Journal of Educational Science and Technology, Vol. 5, no. 1, pp. 39-48, 2019 https://doi.org/10.26858/est.v5i1.8231

[15] Darmaji., Astalini., D. A. Kurniawan, H.Parasdila, Irdianti., Susbiyanto., M. Ikhlas, , Kuswanto, "E-Module Based Problem Solving in Basic Physics Practicum for Science Process Skills," International Journal of Online and Biomedical Engineering (IJOE), 15 (15). 4-17, 2019

[16] Maison, Darmaji, Astalini, D. A. Kurniawan, P. S. Indrawati, "Science Process Skills And Motivation. Humanities \& Social Science Reviews (HSSR)”, vol. 7 no.5, pp. 48-56, 2019

[17] Darmaji, D. A. Kurniawan, and Irdiant, "Physics education students' science process skills" International Journal of Evaluation and Research in Education (IJERE), vol. 8 no.2, pp. 293-298, 2019

[18] Astalini, D. A. Kurniawan, R. Perdana, and H. Pathoni, "Identifikasi Sikap peserta didik terhadap mata pelajaran fisika di Sekolah menengah Atas Negeri 5 Kota Jambi” Unnes Physics Education Journal, Vol. 8, no. 1, pp. 34-43, 2019 https://doi.org/10.15294/upej.v8i1.29510

[19] M. Bulunuz, "The Role of Playful Science in Developing Positive Attitudes Towards Teaching Science in a Science Teacher Preparation Program," Eurasian Journal Educational Research, Vol. 58, pp. 67-88, 2015 http://dx.doi.org/10.14689/ejer.2014.58.2

[20] Maison, Astalini, D. A. Kurniawan, R. Perdana, L. Anggraini, "The Phenomenon of Physicology Senior High School Education: Relationship of Students' Attitudes towards Physics, Learning Style, Motivation," Universal Journal of Educational Research. Vol.7 no.5, pp. 2199-2207, 2019 
[21] D. A. Kurniawan, Darmaji., Astalini., P. Sefiah, "Description of Science Process Skills for Physics Teacher's Candidate," Azerbaijan Journal of Educational Studies. Vol. 684, no.3, pp. 71-85,2019

[22] Astalini, D. A. Kurniawan, Darmaji, L. R. Sitorus, and R. Perdana, "Characteristic Of Students Attitude To Physics In Muaro Jambi High School,” Humanities \& Social Science Reviews. Vol. 7, no. 2, pp. 91-99, 2019 https://doi.org/1018510/hssr.2019.7210

[23] F. W. Yunuz and Z. M. Ali, "Urban Students' Attitude towards Learning Chemistry," Procedia-Social and Behaviorial Sciences, vol. 68, pp. 295-304, 2012 https://doi.org/10.1016/j.sbspro.2012.12.228

[24] Astalini., Darmaji, D. A. Kurniawan, R. Melsayanti, "E-Assessment of Student Perception of Natural Science Based on Seska in Middle School Students in Indonesia," International Journal of Scientific \& Technology Reseaerch, vol. 8, no. 9, pp. 858-863, 2019

[25] Darmaji, D., Kurniawan, D. A., and Irdianti, "Physics education students' science process skills," International Journal of Evaluation and Research in Education (IJERE), vol. 8, no. 2, pp. 293-298, 2019

[26] S. Nurhasanah, and A. Sobandi, "Minat belajar sebagai determinan hasil belajar siswa," Jurnal pendidikan manajemen perkantoran, Vol. 1, No. 1, pp. 128-135, 2016

[27] D. Kurniawan, and D. U. Wustqa, "Pengaruh perhatian orangtua, motivasi belajar, dan lingkungan sosial terhadap prestasi belajar matematika siswa SMP,” Jurnal riset pendidikan matematika, Vol.1, No.2, 176-187, 2014 https://doi.org/10.21831/jrpm.v1i2.2674

[28] H. Bacanli, M. A. Dombayci, M. Demir, and S. Tarhan, "Quadruple Thinking: Creative Thinking," Procedia Social and Behavioral Science, Vol. 12, pp. 536-544, 2018 https://doi.org/10.1016/j.sbspro.2011.02.065

[29] Syahrial, Asrial, D. A. Kurniawan, F. Chan, A. Hariandi, R. A. Pratama, P. Nugroho, R. Septiasari, "The Impact of Ethnoconstructivism in Social Affairs on Pedagogic Competences," International Journal of Evaluation and Researcn in Education (IJERE), Vol.8, No.3, pp.409-416, 2019

[30] Syahrial, Asrial, D. A.Kurniawan, P. Nugroho, R. Septiasari, R.A Pratama, R.Perdana, "Increased Behavior of Students' Attitudes to Cultural Values using the Inquiry Learning Model Assisted by Ethnoconstructivism" Journal of Educational Science and Technology, Vol. 5, No.2, pp.176-188, 2019

[31] T.B. Ward, S.M. Smith, and R.A. Finke, Creative cognition. In: Sternberg, R.J. (Ed.), Handbook of Creativity. Cambridge University Press, Cambridge, pp. 189-212, 1999

[32] L. S. Colzato, S. M. Ritter, and L. Steenbergen, "Transcutaneous Vagus nerve stimulation (tVNS) enhances divergent thinking” Neuropsychologia, vol. $\quad 111, \quad$ pp. $\quad 72-76, \quad 2018$ https://doi.org/10.1016/j.neuropsychologia.2018.01.003

[33] P. G. Rivas, "Strategies for teaching and dissemination of artistic heritage by promoting critical and creative thinking among future Primary Education teachers," Procedia - Social and Behavioral Science, vol. 237, pp. 717722, 2017 https://doi.org/10.1016/j.sbspro.2017.02.112

[34] L. Cohen, L. Manion, and K. Morrison, Research Methods In Education : Routledge, 2005

[35] J. W. Creswell, Educational Research: Planning, Conducting, And Evaluating Quantitative And Qualitative Research. New York: Pearson, 2012

[36] F. N. Kerlinger, Foundations of behavioral research. Yogyakarta: Gadjah Mada University Press, 2014

[37] Cohen, L., Manion, L., \& Morrison, K. Research Methods In Education : Routledge, 2005

[38] D.M Gall, et al. Education Research an introduction seventh edition. USA: Pearson Education.Inc, 2003

[39] J.W. Creswell, Educational Research: Planning, Conducting, And Evaluating Quantitative And Qualitative Research. New York: Pearson, 2012

[40] L. Cohen, L. Manion, and K. Morrison, Research Methods In Education : Routledge, 2005

[41] Astalini, D. A. Kurniawan, Darmaji, L. R. Sitorus, and R. Perdana, "Characteristic Of Students Attitude To Physics In Muaro Jambi High School,” Humanities \& Social Science Reviews. Vol. 7, no. 2, pp. 91-99, 2019 https://doi.org/1018510/hssr.2019.7210

[42] C. Y. Piaw, "Building a test to assess creative and critical thinking simultaneously," Procedia Social and Behavioral Sciences, vol. 2, pp. 551-559, 2010 https://doi.org/10.1016/j.sbspro.2010.03.062

[43] Asrial, Syahrial, D. A. Kurniawan, M. Subandiyo, N.Amalina, "Exploring obstacles in language learning among prospective primary school teacher," International Journal of Evaluation and Research in Education (IJERE), Vol.8, No. 2, pp. 249-254, 2019

[44] Asrial., Syahrial., Kurniawan, D. A., Perdana, R., Nugroho, P. "Supporting Technologi 4.0: Ethnoconstructivist Multimedia for Elementary Schools". International Journal of Online and Biomedical Engineering (iJOE). 15(9), 4-15. 2019

[45] D. A. Kurniawan, Asrial, Syahrial, W. S. Salsabila, E. F.Kurniawati, Q. S. Anandari, R. Perdana, A. Lumbantoruan, N.R. Nasih, S. C. Samosir, U.P. Dewi, "Etnoscience Investigation in Pimary Schools: Impact on Science Learning," Universal Journal of Educational Research Vol. 7, No.12, pp. 2789-2795, 2019.

[46] Astalini, D. A.Kurniawan, and L. Anggraini, "Correlation Between Confidence With Attitude Toward Science In Secondary School In Indonesia,” Bjes, Vol. 20, No. 1, pp. 30-45, 2019 
[47] T. M. Akey, School Context, Student Attitudes and Behavior, and Academic Achievement: An Exploratory Analysis. MDRC, 2006 https://files.eric.ed.gov/fulltext/ED489760.pdf

[48] S. Nurhasanah, and A. Sobandi, "Minat belajar sebagai determinan hasil belajar siswa," Jurnal pendidikan manajemen perkantoran, Vol. 1, No. 1, pp. 128-135, 2016

[49] F. W. Yunuz, \& Z. M. Ali, "Urban Students' Attitude towards Learning Chemistry," Procedia-Social and Behaviorial Sciences, vol. 68, pp. 295-304, 2012 https://doi.org/10.1016/j.sbspro.2012.12.228

[50] F. W. Yunuz, \& Z. M. Ali, "Urban Students' Attitude towards Learning Chemistry," Procedia-Social and Behaviorial Sciences, vol. 68, pp. 295-304, 2012 https://doi.org/10.1016/j.sbspro.2012.12.228 